\title{
A Pilot Study of Relationships between Pitch Register and Dynamic Level and Vibrato
}

Rate and Width in Professional Violinists

By: $\underline{\text { Rebecca B. Macleod }}$

MacLeod, R. B. (2010). A pilot study of relationships between pitch register and dynamic level and vibrato rate and width in professional violinists. String Research Journal, 1, 75-83. Copyright (C2010 American String Teachers Association. DOI: 10.1177/194849921000100105

Made available courtesy of SAGE Publications: https://doi.org/10.1177/194849921000100105

(c) (i) $(9$

CO ${ }_{\mathrm{EY}} \mathrm{NO}$ This work is licensed under a Creative Commons

Attribution-NonCommercial-NoDerivatives 4.0 International License.

\section{Abstract:}

The purpose of this research was to investigate whether dynamic level and pitch register influence vibrato width and rate of four professional violin soloists. Data were obtained from recordings of Bell, Midori, Mutter, and Perlman. Analysis of data indicated that both dynamic level and pitch register influenced the vibrato width of the performers, whereas vibrato rate was influenced by dynamic level but not pitch register. Artists' vibrato was wider in the upper register than in the lower register. Mean width of the soloists' vibrato was 63 cents (slightly more than one-quarter tone) and mean vibrato rate was $6.63 \mathrm{~Hz}$. Discussion includes implications for string pedagogy and suggestions for additional research.

Keywords: vibrato | string instruments | violin performance | dynamics | pitch register | string pedagogy

Article:

Vibrato has been identified as essential in string performance. However, many young students struggle to acquire this skill. Furthermore, pedagogues disagree on some of the fundamental components of vibrato. Aspects such as appropriate width, rate, and purported pitch center are frequently debated. In order to better inform pedagogical practice, in this study I investigated some of the fundamental characteristics of artist-level violinists' vibrato. The individual components of an artist level vibrato may serve as a pedagogical model for teachers to increase clarity and effectiveness in instruction. Artist performers' vibrato may also serve as an inspiration for students as they learn to develop their own.

Pedagogues and performers agree that beautiful vibrato is balanced, even, and free of tension (Applebaum, 1986; Fischbach, 1998; Galamian, 1962; Gillespie, 1996; Lucktenberg, 1994; Potter 1980; Rolland, Mutchler, \& Hellebrandt, 2000; Young 1999). However, the initial motion involved in producing a vibrated tone provokes disagreement among pedagogues. Many performers and pedagogues imply a backward motion in which the pitch oscillates below the 
conceived pitch (Applebaum, 1986; Galamian, 1962; Hamann \& Gillespie 2004; Lucktenberg, 1994), some imply a forward motion (Fischer, 1997; Rolland et al., 2000), and still others profess that vibrato oscillates both above and below the pitch center (Fischbach, 1998; Rolland, et al., 2000; Young, 1999).

Research has attempted to measure purported pitch centers and has produced mostly consistent results. Early investigations of violin vibrato by Seashore and associates (1936) revealed that the mean pitch of a vibrated tone corresponded to the written pitch on the score for the majority of tones analyzed with the exception of tendency tones. More recent investigations of high school and college violin and cello players reinforced Seashore's findings. Both high school and college participants performed vibrato that oscillated above and below the pitch center (Geringer \& Allen, 2004; Geringer, Allen, \& MacLeod, 2005). In contrast, Papich and Rainbow $(1974,1975)$ reported that performers demonstrated an initial sharpening once vibrato commenced and that the oscillations were primarily above the pitch center. Despite the belief that oscillations above the intended pitch will be perceived as sharp (Galamian, 1962; Lucktenberg, 1994), research has found that listeners perceive the mean pitch or center of a vibrated tone, not the highest frequency of the vibration (Brown \& Vaughn, 1996; Geringer, Allen, \& MacLeod, 2010).

The appropriate rate for an expressive vibrato suggested by performers and pedagogues varies from 5 to $7.5 \mathrm{~Hz}: 5$ to $7 \mathrm{~Hz}$ (Potter, 1980); $5 \mathrm{~Hz}$ (Applebaum, 1986); 6 to $7.5 \mathrm{~Hz}$ (Fischbach, 1998); and 6.5 Hz (Rolland et al., 2000). Empirical research has investigated vibrato rates of professional violinists, violists, cellists, teachers and students, high school and college violin and cello students and results have varied. Mean ranges encompass $5.5 \mathrm{~Hz}$ to $7 \mathrm{~Hz}$ (Geringer \& Allen, 2004; Hollinshead, 1932; Papich \& Rainbow, 1974; Reger, 1932; Seashore, 1936). Seashore (1936) analyzed vibrato and discovered that the rate was approximately $6 \mathrm{~Hz}$ and constant. Hollinshead (1932) measured 11 professional violinists performing 11 different pieces and found that the mean vibrato rate was $7 \mathrm{~Hz}$. Reger (1932) measured the vibrato rate of professional violinist Fritz Kreisler, three violin teachers, and four violin students and determined that the vibrato rate varied: Kreisler $(6.9 \mathrm{~Hz})$, violin teachers $(5.95 \mathrm{~Hz})$, and violin students $(6.35 \mathrm{~Hz})$. Papich and Rainbow (1974) determined that vibrato rate was different between the string instruments; violinists vibrated at $6.5 \mathrm{~Hz}$, cellists at $5 \mathrm{~Hz}$, and bassists at $4 \mathrm{~Hz}$. More recently, Geringer and Allen (2004) measured the vibrato of high school and college violin and cello players and found that the vibrato rate was approximately $5.5 \mathrm{~Hz}$. It is possible that professional artists vibrate at a faster rate than professional teachers and students, though caution must be taken due to the small sample size in Reger's study. No conclusions were drawn concerning the difference in rate between teachers and students in the study.

Some pedagogues have stated that the speed or rate of vibrato is partially dependent on the dynamic level of the passage (Galamian, 1962; Gillespie, 1996). Reger (1932) investigated the effect of dynamic level on vibrato rate and found that fortissimo excerpts were performed with a vibrato rate $.13 \mathrm{~Hz}$ faster than pianissimo passages. Galamian (1962) believed that vibrato corresponded primarily to the dynamics of the bow and required greater width and intensity during forte and a more subdued, narrow and slow vibrato during piano passages.

A larger number of pedagogues and performers have suggested that the width of vibrato varies in accordance with dynamic level (Galamian, 1962; Gillespie, 1996; Potter, 1980; Rolland, et al., 2000; Young, 1999). Wide vibrato has been associated with loud passages and narrow vibrato with soft passages (Galamian, 1962; Potter, 1980; Rolland et al., 2000; Young 1999). Seashore (1936) analyzed the violinist Arnold Small and found that the width of his 
vibrato increased during the louder portion of tones and decreased near the end of tones. Reger (1932) found that increases in dynamic level were accompanied by a marked increase in vibrato width of approximately 26 cents.

Pitch register has been noted as a key factor in establishing the appropriate width and speed of vibrato. The kinesthetic space between intervals decreases in the upper register of string instruments, therefore it has been suggested by pedagogues that the width of vibrato decreases in higher registers to prevent oscillations that exceed one half step (Applebaum, 1986; Lucktenberg, 1994). Some studies have found that lower string instruments vibrate at slower rates than violins, which may imply an effect of pitch register on vibrato rate (Papich \& Rainbow, 1974; Reger, 1932). Reger compared mean vibrato rates of two professional violinists, one professional violist, and one professional cellist, and discovered that mean vibrato rates of violinists $(6.9 \mathrm{~Hz})$ were faster than mean vibrato rates for cellists $(6.3 \mathrm{~Hz})$ and violists $(6.1 \mathrm{~Hz})$. More recently, Geringer and Allen (2004) found that the width, not the rate, of vibrato was different between high school and college violin and cello players. Violinists' average vibrato width was approximately 34 cents, compared to 26 cents for the cellists; no significant difference in vibrato rate was found. Cheslock (1931) compared four tones (F3, C4, G5, D5) in fifth position with the second finger on each string and found no difference in vibrato rate or width.

Style and performance context may further impact vibrato rate and width. Fischbach (1998) suggests that solo performers often vibrate a total width of a half step while ensemble players vibrate about a quarter tone. Hollinshead (1932) measured the average vibrato width of artist performers and determined that the mean width of violinist's vibratos was .26 tone (52 cents). Pedagogues and limited research have suggested that an individual's vibrato may be affected by a multitude of contextual factors, including solo versus ensemble playing, the tempo and style of a piece, pitch register, dynamic level, and note length. The purpose of this research was to explore the possible relationship between dynamic level and pitch register and the width and rate of professional violin soloists' vibratos.

\section{Method}

Four well-known violin soloists (Midori, Bell, Perlman, Mutter) were selected for this study in order to analyze the vibrato of established professional soloists. Recent artists were used to control for possible effects of recording quality on pitch analysis. The first movement of the Violin Concerto in G Minor, Op. 26 by Max Bruch was chosen. This selection was chosen for two reasons: measures six and ten are cadenzas performed without orchestral accompaniment and it covers a three-octave range on the violin, $\mathrm{G}_{3}$ to $\mathrm{G}_{6}$.

A recording of each artist performing the first movement of the Bruch violin concerto was copied from the original recording on compact disc to computer hard drive, and then analyzed using Praat software (Praat v.4.1.4, 2004). Sustained tones that contained a minimum of three complete vibrato cycles were isolated for each artist (Mutter, 14; Midori, 14; Bell, 17; Perlman, 16) and the following characteristics were measured and recorded: mean pitch (frequency in $\mathrm{Hz}$ ), minimum and maximum pitch in a given vibrato $(\mathrm{Hz})$, mean intensity (in relative $\mathrm{dB})$, and rate $(\mathrm{Hz})$. The minimum and maximum frequencies of each isolated note were then converted to cents to determine the width of the vibrato. The vibrato rate for each tone was calculated by dividing the number of complete vibrato cycles during the middle portion of a tone by the duration of those cycles. To compare possible differences in vibrato as a result of dynamic changes, tones with a diminuendo/crescendo were isolated and analyzed during the loudest and 
softest portions of the same note.

\section{Results}

Each soloist's performance was analyzed with regard to the following dependent variables: pitch register (expressed in $\mathrm{Hz}$ ), dynamic level (relative dB level), vibrato rate (Hz), and width (cents). Correlations between pitch register and vibrato rate, pitch register and vibrato width, dynamic level and vibrato rate, and dynamic level and vibrato width were computed for each artist individually and overall (see Tables 1 and 2). Moderate positive correlations were found for dynamic level and rate $(\mathrm{r}=.44)$, dynamic level and width $(\mathrm{r}=.49)$, and pitch register and width $(\mathrm{r}=.42)$, but not for pitch register and rate $(\mathrm{r}=-.08)$.

Table 1. Correlations Between Dynamic Level and Vibrato Rates and Widths of the Four Artists

\begin{tabular}{|l|c|c|}
\hline Artist & Rate r & Width r \\
\hline Perlman & .44 & .63 \\
\hline Bell & .64 & .58 \\
\hline Mutter & .52 & .38 \\
\hline Midori & .93 & .63 \\
\hline Overall & .44 & .49 \\
\hline
\end{tabular}

A moderate correlation $(\mathrm{r}=.44)$ was found overall between the dynamic level of a tone and the rate of vibrato for the four artists combined. Further analysis revealed that the correlation between dynamic level and vibrato rate varied considerably between individual performers (Perlman, $\mathrm{r}=.44$; Bell, $\mathrm{r}=.65$; Mutter, $\mathrm{r}=.53$; Midori, $\mathrm{r}=.93$ ). The strongest correlation was found in Midori's performance, where the relationship between dynamic level and vibrato rate produced an r of .93 (see Table 1).

Moderate positive correlations were found for dynamic level and vibrato width $(r=.49)$ and pitch register and width $(\mathrm{r}=.42)$ overall. The degree to which vibrato width deviated corresponding to dynamic level and pitch register, also varied from performer to performer (see Tables 1 and 2). Correlations between dynamic level and vibrato width varied from $r=.38$ (Mutter) to $\mathrm{r}=.63$ (both Perlman and Midori). Three of the artists showed moderate positive correlations between pitch register and vibrato width (Bell, $r=.55$; Mutter, $r=.40$; Midori, $r=$ .57). The width of Perlman's vibrato did not correspond with changes in pitch register $(r=.09)$ (see Table 2). 
Table 2. Correlations Between Pitch Register and Vibrato Rates and Width of the Four Artists

\begin{tabular}{|l|c|c|}
\hline Artist & Rate r & Width r \\
\hline Perlman & .14 & .09 \\
\hline Bell & -.28 & .55 \\
\hline Mutter & -.09 & .40 \\
\hline Midori & -.16 & .57 \\
\hline Overall & -.08 & .42 \\
\hline
\end{tabular}

The overall mean of the four performers' vibrato width was 62.87 cents (Mutter, $\mathrm{M}=67.9 \mathrm{c}$; Midori, $\mathrm{M}=59.56 \mathrm{c}$; Bell, $\mathrm{M}=61.06 \mathrm{c}$; Perlman, $\mathrm{M}=62.97 \mathrm{c}$ ), over a quartertone $(50 \mathrm{c})$. Notes with a frequency above A5 $(880 \mathrm{~Hz})$ generally produced wider vibrato $(\mathrm{M}=67.9 \mathrm{c})$ than notes in the lower register $(M=54.7 \mathrm{c})$. The minimum cent deviation produced during vibrato was 24 cents (1/8 tone) and the maximum was 129.2 cents, more than a semitone. Both minimum and maximum widths were produced during tones with fundamental frequencies above $1000 \mathrm{~Hz}$.

Table 3. Performers' Means for Vibrato Rates and Widths

\begin{tabular}{|l|c|c|}
\hline Artist & Mean Rate & Mean Width \\
\hline Perlman & $6.46(\mathrm{~Hz})$ & $62.97($ Cents $)$ \\
\hline Bell & 6.24 & 61.06 \\
\hline Mutter & 6.73 & 67.90 \\
\hline Midori & 7.10 & 59.56 \\
\hline Overall & $6.63(\mathrm{sd}=.37)$ & $62.87(\mathrm{sd}=3.63)$ \\
\hline
\end{tabular}

The mean vibrato rate of the four performers was $6.63 \mathrm{~Hz}$. The average vibrato rates also varied between performers (Mutter, $\mathrm{M}=6.7 \mathrm{~Hz}$; Midori, $\mathrm{M}=7.1 \mathrm{~Hz}$; Bell, $\mathrm{M}=6.2 \mathrm{~Hz}$; Perlman, $\mathrm{M}=$ $6.46 \mathrm{~Hz}$ ) (see Table 3). A relationship was not found between rate of vibrato and pitch register of tones $(\mathrm{r}=-0.08)$. The lack of correlation between vibrato rate and pitch register was the most consistent category between the four performers in this study (see Table 3 ).

\section{Discussion}

Data in this study indicated that vibrato width is related to the dynamic level and pitch register of a given tone, whereas vibrato rate correlates positively with dynamic level, but not the pitch register, of a given tone. While some consistencies were noted between performers, such as the lack of relationship between the rate of vibrato and the pitch register of the note, other 
aspects of vibrato varied from performer to performer. For example, dynamic level and rate produced a moderate correlation of $\mathrm{r}=.44$, however individual performers produced correlations ranging from .93 (Midori) to .44 (Perlman). The degree to which vibrato width related to dynamic level between the four artists may be attributed to a number of additional variables such as: artistic choice, habit strength, chosen tempo, or chance. Further research on this topic, with an increased participant pool, would shed light on the differences between artists.

A consistent observation in this study was the lack of relationship between pitch register and vibrato rate. Results of previous research regarding the vibrato rate of upper and lower string instruments are inconsistent. Allen and Geringer (2004) found no significant difference between the vibrato rate of violinists and cellists, while other studies found that low string instruments vibrated at slower rates than the violin (Papich \& Rainbow, 1974; Reger, 1932).

The excerpt used in this study had a range of over three octaves and it would appear from the results that vibrato rate was not affected by pitch register. It is possible that low string instruments sometimes vibrate at a slower rate for reasons other than pitch register. One possible explanation is the difference in size between the string instruments. Production of an identical vibrato width between a violinist and a cellist would require the cellist to move farther on the fingerboard and therefore faster, to maintain the same rate. Reger (1932) concluded that the difference in vibrato rates was not due to size, but artistic choice. More research is needed to clarify whether there is a difference, and if so, the reasons for the difference.

A positive correlation was found between pitch register and vibrato width. Contrary to some pedagogical suggestions that higher frequencies require a narrower vibrato (Applebaum, 1986; Lucktenberg, 1994), analysis of performances in this study found that notes above $900 \mathrm{~Hz}$ (Bb5) generally were associated with wider vibrato $(\mathrm{M}=67.9 \mathrm{c})$ than notes in lower registers $(\mathrm{M}$ $=54.7 \mathrm{c}$ ). Although this difference is relatively small, it demonstrates that width does not decrease in the upper range; rather it increases or remains the same despite the reduction in physical distance required to perform comparable vibrato. This information seems important when describing the correct vibrato motion to students. Requiring the student to minimize the width of the vibrato in the upper positions to maintain a musical width of one-quarter tone may increase the possibility of tension in the left hand. Based on the information collected from these four artists, it appears acceptable for width to increase in the upper positions of the instrument.

The degree of correspondence between pitch register and width did vary among individual artists. Midori, Bell, and Mutter all demonstrated wider vibrato in the upper register than in the lower register. These performers' average increase was 13 cents in the higher register. Perlman was the exception, as his vibrato did not vary with pitch register. The difference in his vibrato width between the lower and higher registers was only 2.3 cents.

The mean vibrato width of the four artists was slightly greater than a quartertone and sometimes approached a half step. The average vibrato rate was $6.63 \mathrm{~Hz}$. Midori demonstrated the fastest mean vibrato rate, averaging $7.1 \mathrm{~Hz}$, and Bell demonstrated the slowest mean vibrato rate, $6.24 \mathrm{~Hz}$. These rates correspond to some of the rates proposed by pedagogues and early researchers (Fischbach, 1998; Hollinshead, 1932; Potter, 1980; Reger, 1932; Rolland et. al., 2000; Seashore, 1936).

Analyses in this study show that vibrato width and rate are not constant and vary from person to person, based on musical choice, dynamic level, and pitch register, and probably other factors. One practical suggestion that teachers might make is to have students vary the width and rate of their vibrato for expressive purposes. In particular, during forte passages, a wider vibrato appears to be utilized while a narrower vibrato may be used during piano passages. It seems 
prudent to recognize that vibrato rates and widths are affected by many contextual factors and avoid making global statements that do not apply to every musical situation, such as limiting the width in the upper range of the instrument or suggesting that all vibrato width should be around one-quarter tone. The individual artists in this study varied the width of vibrato sometimes to over one half step.

Caution should be taken when considering the results of this study. A small sample size was analyzed with only four artists performing the opening of only one piece. Increasing the number of performers and pieces or including stylistic and contextual variables may produce entirely different results. An increased sampling of the same performers could alter the results of this study. More information is needed to clarify the composition of a beautiful vibrato. String students should have the opportunity to learn to vibrate with a beautiful sound. Further research examining other contextual factors will help shed light on this musical and technical challenge. An investigation of professional musicians and preferences of various vibrato rates and widths in many contexts is important to advancing a clear pedagogical method for teaching vibrato. Further investigations that include the physical aspects involved in creating the correct vibrato motion are also necessary to advance vibrato teaching techniques. Carefully designed research that provides additional information is needed to accurately describe and guide further teaching practice.

\section{References}

Applebaum, S. (1986). Vibrato. In The Art and Science of String Performance (pp. 64-71). Van Nuys, CA: Alfred Publishing Company, Inc.

Brown, J. C. \& Vaughn, K. V. (1996). Pitch center of stringed instruments vibrato tones. Journal of the Acoustical Society of America, 100(3), 1728-1735.

Fischbach, G. (1998). The birth of a vibrato. American String Teacher, 48(4), 28-35.

Fischer, S. (1997). Vibrato. In Basics: 300 exercises and practice routines for the violin/viola (pp. 662-663). London: Edition Peters.

Galamian, I. (1962). Vibrato. In Principles of Violin Playing and Teaching (pp. 37-43). Englewood Cliffs, NJ: Prentice-Hall.

Geringer, J. M. \& Allen, M. L. (2004). An analysis of vibrato among high school and university violin and cello students. Journal of Research in Music Education, 52, 167-178.

Geringer, J. M., Allen, M. L., \& MacLeod, R. B. (2005). Initial movement and continuity in vibrato among high school and university string players. Journal of Research in Music Education, 53, 248-259.

Geringer, J. M., Allen, M. L., \& MacLeod, R. B. (2010). String vibrato: Research related to performance and perception. String Research Journal, I, 7-23.

Gillespie, R. (1996). Vibrato: What do we know from research about this shaking, waving, wobbling thing anyway? American String Teacher, 46(1), 91-92.

Hamann, D. \& Gillespie, R. (2004). Strategies for teaching strings: Building a successful string and orchestra program. New York: Oxford University Press.

Hollinshead, M. T. (1932). A study of the vibrato in artistic violin playing. In C. E. Seashore (Ed.), University of Iowa studies in the psychology of music: Vol. I. The Vibrato (pp. 281-288). Iowa City: University of Iowa.

Lucktenberg, J. (1994). Developing violin vibrato. The Instrumentalist, 48(10), 32-36.

Papich, G. \& Rainbow, E. (1974). A pilot study of performance practices of twentieth-century 
musicians. Journal of Research in Music Education, 22, 24-34.

Papich, G. \& Rainbow, E. (1975). Research in the performance practices of musicians. Psychology of Music, 22, 4-8.

Potter, L. (1980). The Vibrato. In The Art of Cello Playing (2nd ed., pp. 108-109). Princeton, NJ: Summy-Birchard Music.

Praat [Computer software]. (2007). Amsterdam, The Netherlands: Institute of Phonetic Sciences, University of Amsterdam (Version 4.6.1).

Reger, S. N. (1932). The string instrument vibrato. In C. E. Seashore (Ed.), University of Iowa studies in the psychology of music: Vol. I. The vibrato. (pp. 305-340). Iowa City: University of Iowa.

Rolland, P., Mutchler, M., \& Hellebrandt, F. (2000). First steps in teaching vibrato. In The teaching of action in string playing. (3rd ed., pp. 153-161). Urbana, Illinois: Illinois String Research.

Young, P. (1999). Great shakes: Matchboxes and sponges - expert tips on teaching vibrato. Strad, 110 (1313), 934-937.

Seashore, C. E. (1936). Studies in the Psychology of Music: Psychology of the vibrato in voice and instrument. Iowa City: University of Iowa. 